\title{
Exercise-Induced Enhancement of Lipid Peroxide Metabolism in Tissues and Their Transference into the Brain in Rat
}

\author{
Masashige SuzukI, ${ }^{1, *}$ Shinichiro KATAMINE, ${ }^{2}$ and Sachie TATSUMI $^{3}$ \\ ${ }^{1}$ Laboratory of Biochemistry of Exercise and Nutrition, \\ Institute of Health and Sports Sciences, \\ University of Tsukuba, Sakura-mura, \\ Niihari-gun, Ibaraki 305, Japan \\ ${ }^{2}$ Research Center, Nihon Nosan Kogyo K. K., \\ Hinode-cho, Funabashi, Chiba 273, Japan \\ ${ }^{3}$ Kyoritsu Women's Junior College, \\ Hitotsu-bashi, Chiyoda-ku, Tokyo 101, Japan
}

(Received August 11, 1982)

Summary This study was conducted to investigate whether a moderate running exercise would enhance or prevent the lipid peroxidation in animal body and also stimulate or depress the degradation-excretion of lipid peroxides (LIPOX, thiobarbituric acid reactive substances determined as malon dialdehyde) in young female rats. Compared with sedentary rats, voluntary wheel-running exercised rats did not show any significant difference in total LIPOX contents in plasma and several tissues including brain, and whole body during 4 weeks of experiment with a vitamin E-free low LIPOX diet. On the contrary, when rats were previously fed a high LIPOX diet and then allowed voluntary exercise with a vitamin E-added low LIPOX diet, total LIPOX contents per whole body reduced significantly faster in the exercised rats than in the sedentary controls during 2 weeks of exercise. At that period, LIPOX were progressively increased in the brain in both groups of animals, but was significantly greater in the exercised group. Interestingly, more than $80 \%$ of total LIPOX contents in whole body were found to be stored in carcass portions regardless of greater or lesser amounts of LIPOX contents in rats. These data suggest that a moderate exercise of several weeks might enhance the degradation-excretion of LIPOX but not the formationaccumulation of LIPOX in rats. Exercise also seems to modulate LIPOX transference among tissues.

Key Words voluntary running exercise, lipid peroxide, brain, carcass, whole body, rat

${ }^{1}$ 鈴木正成, ${ }^{2}$ 片塞伸一郎, ${ }^{3}$ 巽さち江

* To whom correspondence should be addressed. 
The elevation of lipid peroxide (LIPOX) levels in the blood and tissues of animals has generally been considered as one of the causes that enhance the process of ageing and increase the prevalence of cerebral and cardiovascular diseases. Several papers have recently reported increased levels of LIPOX (defined as thiobarbituric acid reactive substances, TBARS) in erythrocytes of horses (1) and in skeletal muscle and liver of rats (2) after an exhaustive exercise. In addition, expired pentane, which is thought as a peroxidation product from $\omega-6$ series of fatty acids, was reported to be increased in man during bicycle ergometer exercise (3) and in rats after a bout of exhaustive swimming exercise (4). On the other hand, a moderate swimming exercise training for several weeks has been reported to reduce plasma and liver LIPOX contents in rats (5).

These findings, however, are not clear as to whether exercise enhance or lower lipid peroxidation in animal body, since exercise may have the effects on the LIPOX distribution among organs and tissues without changing the total content of LIPOX in the whole animal body. Additionally, the elevated pentane output in the expired gas may result from hyperventilation per se during exercise.

The present study, therefore, was carried out in an effort to elucidate whether exercise would enhance or prevent the lipid peroxidation and stimulate or depress the degradation-excretion of LIPOX in rats. For these purposes, the estimation of total content and distribution of LIPOX in the whole animal body was conducted in so designed experimental animals.

\section{EXPERIMENTAL}

Two sets of experiments were conducted using female JCL ${ }^{\circledR}$-Sprague-Dawley rats (CLEA Japan Inc., Tokyo). Compositions of experimental diets and feeding schedules were shown in Table 1 and Fig. 1, respectively. Animals were cared in a temperature controlled room $\left(22 \pm 1^{\circ} \mathrm{C}\right)$ with the lights on between $07.00-19.00 \mathrm{hr}$ with free access to water.

Experiment 1. To study the effects of voluntary running on the formationaccumulation of LIPOX, twenty six rats of 21 days old were used. They were ad libitum fed a vitamin (V.) E-added basal diet for 5 days. Then the feeding pattern was shifted to meal-feeding twice a day $(08.00-09.00 \mathrm{hr}$ and $20.00-21.00 \mathrm{hr}$ ). Rats were meal-fed a V.E-free basal diet for 5 days and a V.E-free low LIPOX diet for the successive 28 days of an exercise period. This V.E-free low LIPOX diet was prepared to minimize dietary supply of LIPOX but allow lipid peroxidation in animal body during the exercise period. On the previous day of switching diet from the basal diet to the low LIPOX diet, 6 rats were killed at $13.00 \mathrm{hr}$, and the remaining rats were divided into sedentary (10 rats) and exercised (10 rats) groups. Rats of the sedentary group were individually housed in ordinary cages, and those of the exercised group in cages with revolving wheels (6). The exercised group was allowed voluntary running in wheels during $24 \mathrm{hr}$ daily.

On the 14-day and 28-day of the exercise period, 5 rats of each group were 


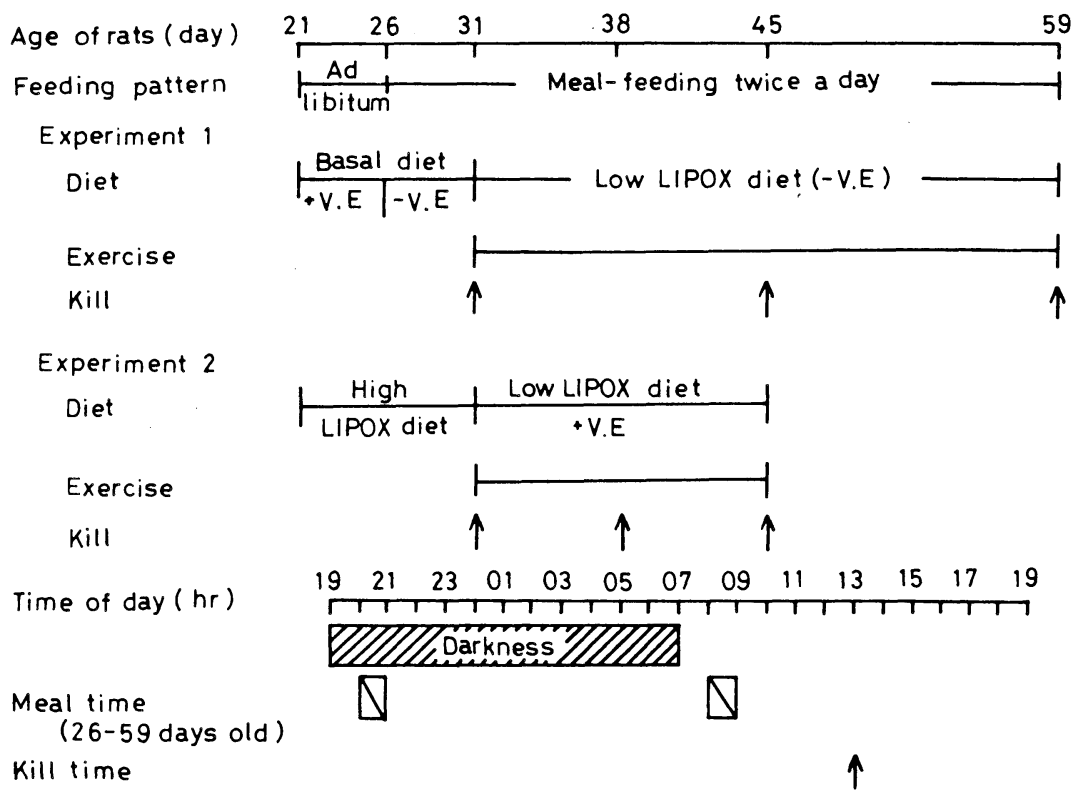

Fig. 1. Feeding schedules for experiments 1 and 2. V.E means vitamin E, and + and - represent added and deprived, respectively. Exercise means voluntary wheelrunning which was allowed only in the exercised group of rats for $24 \mathrm{hr}$.

killed by decapitation at $13.00 \mathrm{hr}$ with exercise restriction for the exercised rats from $21.00 \mathrm{hr}$ of the previous day of killing. Plasma, liver, heart, lungs, kidneys, perirenal and inguinal adipose tissues, and brain were taken from each rat. Carcass was also obtained from the remaining portion after removing digestive tract, mesenteric adipose tissue and other organs. Obtained organs and tissues were freeze-dried, homogenized in $0.9 \% \mathrm{NaCl}$ solution, and then determined for TBARS contents (7). Plasma TBARS contents were determined by the fluorescence method (8). TBARS levels were expressed as nmol malon dialdehyde (MDA)/tissue or plasma/100 g body weight of rat. Total TBARS contents per whole body were calculated by summing up TBARS contents in the examined tissues and organs per whole rat. Percentage distribution of TBARS in plasma and tissues was also shown. Plasma volume per rat was calculated from the body weight (9).

Experiment 2. To see the effects of voluntary running on the degradationexcretion of LIPOX, another twenty six rats of 21 days old were used. These animals were fed a high LIPOX diet $(51.1 \mu \mathrm{mol} \mathrm{MDA} / 100 \mathrm{~g}$, Table 1) ad libitum for the first 5 days and then meal-fed twice a day (08.00-09.00 hr and 20.00-21.00 hr) for another 5 days. Then the V.E-added low LIPOX diet was fed to minimize both dietary supply of LIPOX and lipid peroxidation in animal body during 14 days of the exercise period. On the previous day of switching diet to the V.E-added low LIPOX diet, 6 rats were killed at $13.00 \mathrm{hr}$ and the remaining rats were divided into a 
Table 1. Composition of experimental diets.

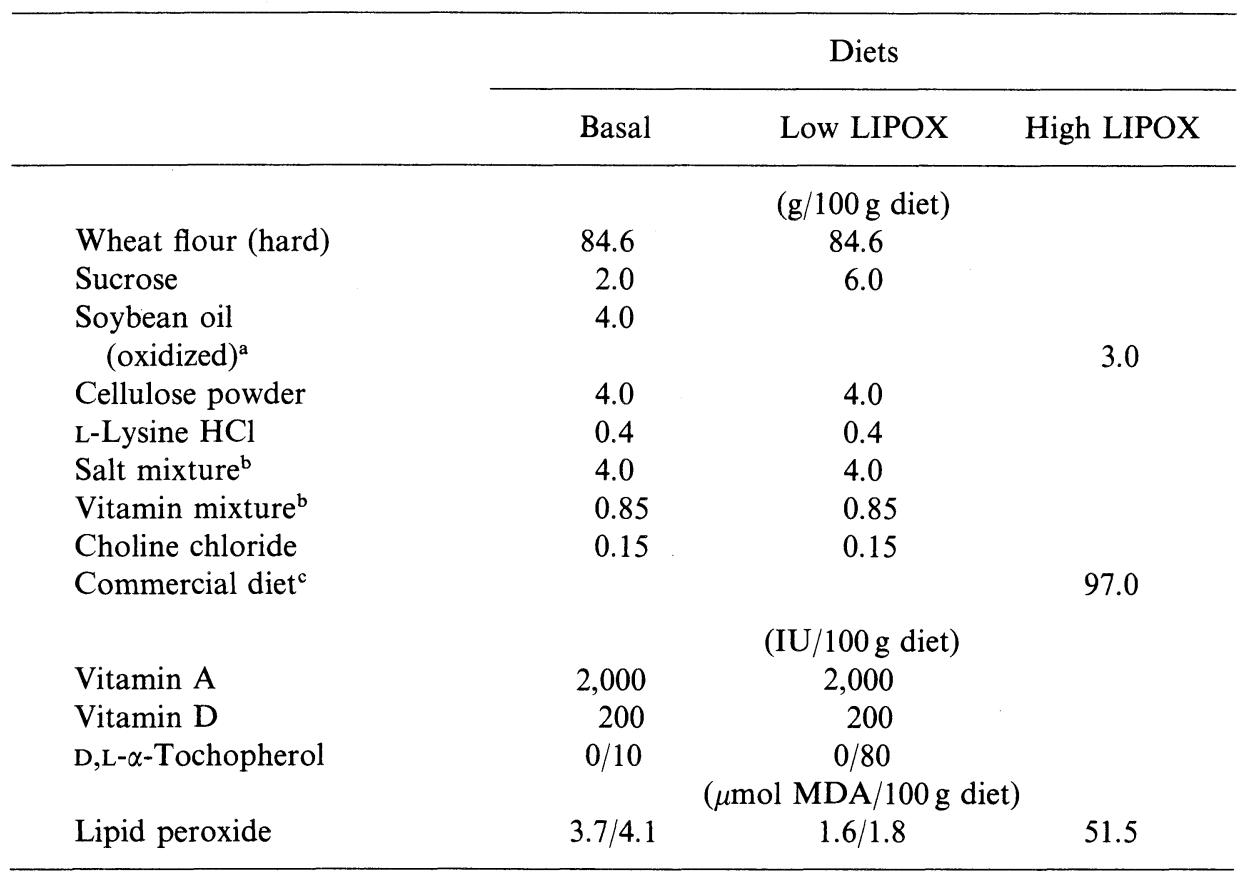

${ }^{\text {a }}$ Soybean oil was oxidized by heating at $110^{\circ} \mathrm{C}$ for $8 \mathrm{hr}$ with aeration. Peroxide value was $197 \mathrm{meq} / \mathrm{kg}(10) .{ }^{\mathrm{b}} \mathrm{CLEA}$ Japan Inc., Tokyo; according to Harper $(11) .{ }^{\mathrm{c}} \mathrm{CE}-7$ (powder); CLEA Japan Inc., Tokyo.

sedentary (10 rats) and an exercised (10 rats) group. Rats of both groups were housed individually and rats of exercised group were allowed voluntary running in wheels as those of experiment 1.

On the 7-day and 14-day of the exercise period, 5 rats of each group were killed at $13.00 \mathrm{hr}$ with exercise restriction for the exercised group from $21.00 \mathrm{hr}$ of the previous day of killing. Plasma, several organs, adipose tissues and carcasses obtained were prepared and determined for TBARS in the same manner as described for experiment 1 .

In both experiments 1 and 2, exercised rats were pair-fed with sedentary rats during the exercise periods. Data were analyzed for significance by the paired $t$-test.

\section{RESULTS}

Effects of voluntary exercise on the formation-accumulation of LIPOX in rats (experiment 1)

Since exercised rats were pair-fed with sedentary rats, weight gain and LIPOX intake over 28 days of the exercise period were almost the same between the groups 
Table 2. Body weight changes and total consumption of food and lipid peroxides during 4 weeks (experiment 1; vitamin E-free low LIPOX diet) and 2 weeks (experiment 2; vitamin E-added low LIPOX diet) of the exercise periods in female rats.

\begin{tabular}{|c|c|c|c|c|c|}
\hline \multirow{2}{*}{$\begin{array}{c}\text { Experimental } \\
\text { period } \\
\text { (age, days) }\end{array}$} & \multirow{2}{*}{ Group } & \multicolumn{2}{|c|}{ Body weight } & \multicolumn{2}{|c|}{ Total consumption } \\
\hline & & Initial & (g) & $\begin{array}{l}\text { Food } \\
\text { (g/rat) }\end{array}$ & $\begin{array}{l}\text { Lipid peroxides } \\
(\mu \mathrm{mol} \mathrm{MDA} / \mathrm{rat})\end{array}$ \\
\hline \multicolumn{6}{|l|}{ Experiment 1} \\
\hline \multirow{2}{*}{$32-45$} & Sedentary & $60 \pm 1$ & $81 \pm 4$ & $113 \pm 8$ & $1.8 \pm 0.1$ \\
\hline & Exercised & $60 \pm 2$ & $80 \pm 3$ & $112 \pm 8$ & $1.8 \pm 0.1$ \\
\hline \multirow{2}{*}{$32-59$} & Sedentary & $60 \pm 2$ & $107 \pm 7$ & $238 \pm 25$ & $3.8 \pm 0.4$ \\
\hline & Exercised & $58 \pm 1$ & $100 \pm 6$ & $243 \pm 7$ & $3.9 \pm 0.1$ \\
\hline \multicolumn{6}{|l|}{ Experiment 2} \\
\hline \multirow{2}{*}{$32-38$} & Sedentary & $86 \pm 2$ & $91 \pm 3$ & $74 \pm 5$ & $1.3 \pm 0.1$ \\
\hline & Exercised & $88 \pm 1$ & $93 \pm 3$ & $72 \pm 5$ & $1.3 \pm 0.1$ \\
\hline \multirow{2}{*}{$32-45$} & Sedentary & $85 \pm 2$ & $97 \pm 4$ & $121 \pm 7$ & $2.2 \pm 0.1$ \\
\hline & Exercised & $84 \pm 3$ & $96 \pm 4$ & $126 \pm 6$ & $2.3 \pm 0.1$ \\
\hline
\end{tabular}

Values are shown as mean \pm SEM for 5 rats of each group.

(Table 2). Exercised rats had a voluntary running activity of $4-8 \mathrm{~km} /$ day.

Changes in plasma and tissue LIPOX contents per rat were illustrated in Fig. 2, and their LIPOX distribution expressed on the basis of $100 \mathrm{~g}$ body weight and as percentages were shown in Table 3 . Although rats were fed a relatively low LIPOX containing diet for the first 10 days in this experiment, their whole body LIPOX contents were unexpectively as high as $16.5 \pm 4.8 \mu \mathrm{mol} \mathrm{MDA} / \mathrm{rat}$ at the age of 31 days (Fig. 2). During the successive 14-day feeding of the low LIPOX diet with voluntary exercise, body LIPOX stores per rat markedly decreased to $40 \%$ of the level at the age of 31 days in exercised rats and to $35 \%$ in sedentary rats. However, in both groups body LIPOX stores per rat increased during the remaining 14 days of the exercise period and reached almost equal levels. The increasing rates were much lower in the exercised group $(13 \%)$ than in the sedentary group $(27 \%)$.

Carcasses accumulated significantly large portions of body total LIPOX stores as $90 \%$ in 31 day old rats and about $80 \%$ in 45 and 59 day old rats in both groups (Table 3). Carcass LIPOX contents per rat considerably decreased through 31 to 45 days of age in both groups of rats, but afterwards increased by age of 59 days. Thus, changes in carcass LIPOX contents were largely responsible for those of whole animal body. The observed increase in carcass LIPOX contents per rat during the final 2 weeks of experiment, as whole body LIPOX stores, were much lower in the exercised group $(13 \%)$ than in the sedentary group $(37 \%)$.

Liver, next to carcass, contained LIPOX highly at about $6 \%$ of body total LIPOX contents per $100 \mathrm{~g}$ body weight in 31 day old rats and $9-13 \%$ in 45 and 59

Vol. 29, No. 2, 1983 


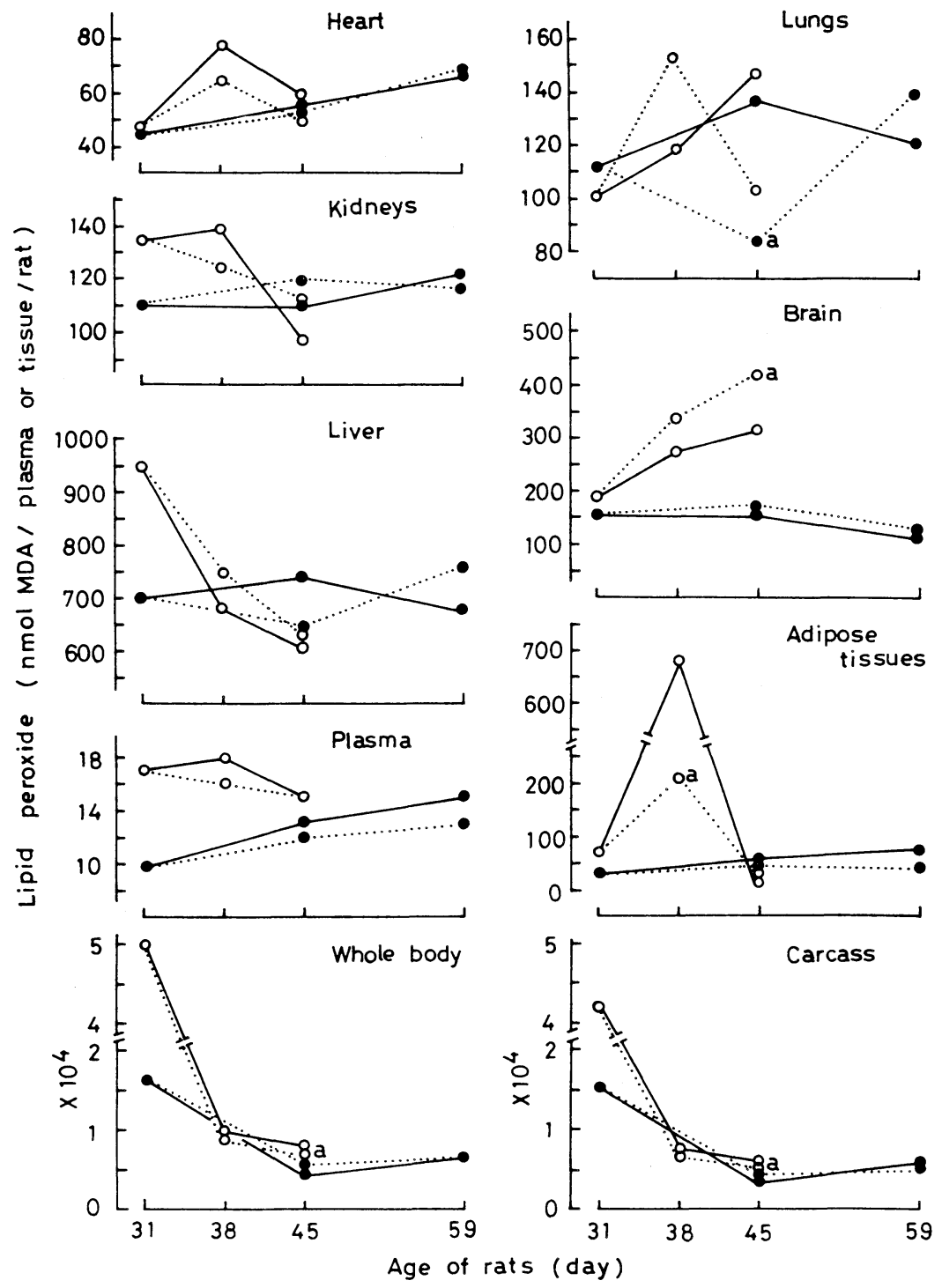

Fig. 2. Effects of voluntary running exercise on plasma, tissue and whole body lipid peroxide contents per rat in female rats (experiments 1 and 2). Each point represents mean for 5 to 6 rats of each group. —_, sedentary group; -----, exercised group. - - - -----, experiment $1 ;-\mathrm{O}-,-\cdots----$, experiment $2 .{ }^{a}$ Significantly different $(p<0.05)$ from the corresponding sedentary group.

day old rats in both groups. During the exercise period, liver LIPOX contents per rat increased at 45 days of age and then decreased at 59 days of age in sedentary rats. In exercised rats, on the other hand, its changing pattern was the reverse of 
sedentary rats. But there was no significant difference in the liver LIPOX contents per rat between the two groups of animals.

Brain stored slightly more LIPOX than kidneys and lungs, and LIPOX storage levels of these three organs were about $2 \%$ each of body total LIPOX stores per $100 \mathrm{~g}$ body weight. Brain LIPOX contents per rat slightly increased and then decreased during the exercise period, and there was no difference between exercised and sedentary rats.

LIPOX contents in kidneys and lungs per rat slightly increased by the end of the exercise period, although a marked decrease occurred in lung LIPOX contents in exercised rats at the age of 45 days. Heart and combined perirenal and inguinal adipose tissues stored LIPOX in less than $1 \%$ each of the body total LIPOX stores per $100 \mathrm{~g}$ body weight. Their storage levels per rat increased over the exercise period in both groups, however, in adipose tissues the accumulation of LIPOX seemed to be lowered during the last 14 days of voluntary running exercise.

Plasma LIPOX contents per rat slightly increased during the exercise period, but there was no significant difference between the two groups.

Effects of voluntary exercise on the degradation-excretion of LIPOX in rats (experiment 2)

During 14 days of the exercise period, weight gain and LIPOX intake were almost the same between sedentary and exercised groups, since the two groups of animals were pair-fed as those in experiment 1 (Table 2). Voluntary running activity of exercised rats was 4-6 km/day during the 2-week exercise period.

Owing to the 10-day feeding of the high LIPOX diet prior to the exercise period, body LIPOX stores per rat at the age of 31 days were significantly as high as about $50 \mu \mathrm{mol} \mathrm{MDA} /$ rat (Fig. 2), which were about 3 times higher than those in experiment 1 . Eighty percent of the initial body total LIPOX stores per rat disappeared during the first 7 days of the exercise period in two experimental groups. In sedentary rats, about $19 \%$ of the body total LIPOX stores per rat at the age of 38 days old further decreased during the last 7 days of experiment. In exercised rats, the reduction of LIPOX stores per rat through 38 to 45 days old was $28 \%$ of the body total LIPOX stores per rat at 38 days old, and the LIPOX contents per rat at the age of 45 days were significantly lower than those in the sedentary rats $(p<0.05)$.

As observed in experiment 1, considerably large portions of total LIPOX in whole body were accumulated in the carcass which stored $97 \%$ or $80-82 \%$ of the body total LIPOX stores per $100 \mathrm{~g}$ body weight before the exercise period or after the 7-day and 14-day voluntary running exercise, respectively (Table 3). In exercised rats, the reduction of carcass LIPOX stores per rat during the exercise period was larger than that in sedentary rats, resulting in significantly lower LIPOX contents in the carcass of exercised rats than those of sedentary rats after 14 days of voluntary exercise. Carcass LIPOX contents per rat at the age of 45 days in both groups were almost similar to those at the ages of 45 and 59 days in experiment 1 .

LIPOX contents in liver, kidneys and plasma per rat decreased during the

Vol. 29, No. 2, 1983 
Table 3. Effects of voluntary running exercise on plasma, tissues and body lipid (experiments 1 and 2).

\begin{tabular}{|c|c|c|c|c|c|c|c|}
\hline \multirow{2}{*}{\multicolumn{2}{|c|}{ Age of rats }} & \multicolumn{6}{|c|}{ Experiment 1} \\
\hline & & \multicolumn{2}{|c|}{31 days } & \multicolumn{2}{|c|}{45 days } & \multicolumn{2}{|c|}{59 days } \\
\hline & & $\begin{array}{c}\text { nmol MDA/ } \\
100 \mathrm{~g} \text { b.w. }\end{array}$ & $\%$ & $\begin{array}{c}\text { nmol MDA/ } \\
100 \text { g b.w. }\end{array}$ & $\%$ & $\begin{array}{c}\text { nmol MDA/ } \\
100 \text { g b.w. }\end{array}$ & $\%$ \\
\hline \multirow{2}{*}{ Plasma } & $\mathrm{Sed}^{1}$ & $17 \pm 1^{a}$ & $0.1^{\mathrm{b}}$ & $16 \pm 1^{\mathrm{a}}$ & $0.2^{\mathrm{b}}$ & $14 \pm 1^{\mathrm{a}}$ & $0.2^{\mathrm{b}}$ \\
\hline & $\mathrm{Ex}^{2}$ & & & $15 \pm 1$ & 0.2 & $13 \pm 1$ & 0.2 \\
\hline \multirow{2}{*}{ Carcass } & Sed & $26,650 \pm 7,956$ & 90.4 & $5,562 \pm 394$ & 77.8 & $5,698 \pm 356$ & 83.5 \\
\hline & Ex & & & $6,645 \pm 690$ & 82.1 & $6,041 \pm 291$ & 82.5 \\
\hline \multirow{2}{*}{ Brain } & Sed & $271 \pm 14$ & 1.3 & $203 \pm 32$ & 2.8 & $110 \pm 10$ & 1.6 \\
\hline & Ex & & & $212 \pm 70$ & 2.7 & $127 \pm 16$ & 1.7 \\
\hline \multirow{2}{*}{ Liver } & Sed & $1,235 \pm 100$ & 5.6 & $908 \pm 113$ & 12.9 & $627 \pm 38$ & 9.3 \\
\hline & Ex & & & $804 \pm 47$ & 10.3 & $777 \pm 116$ & 10.5 \\
\hline \multirow{2}{*}{ Heart } & Sed & $82 \pm 8$ & 0.4 & $67 \pm 5$ & 1.0 & $63 \pm 9$ & 1.0 \\
\hline & Ex & & & $67 \pm 8$ & 0.9 & $69 \pm 8$ & 0.9 \\
\hline \multirow{2}{*}{ Lungs } & Sed & $198 \pm 28$ & 1.0 & $168 \pm 21$ & 2.4 & $114 \pm 12$ & 1.7 \\
\hline & Ex & & & $103 \pm 11^{*}$ & 1.3 & $139 \pm 26$ & 2.0 \\
\hline \multirow{2}{*}{ Kidneys } & Sed & $195 \pm 14$ & 1.0 & $137 \pm 8$ & 1.9 & $114 \pm 4$ & 1.7 \\
\hline & Ex & & & $150 \pm 10$ & 1.9 & $118 \pm 8$ & 1.6 \\
\hline \multirow{2}{*}{$\begin{array}{l}\text { Adipose } \\
\text { tissue }^{3}\end{array}$} & Sed & $61 \pm 16$ & 0.2 & $68 \pm 20$ & 1.0 & $66 \pm 18$ & 1.0 \\
\hline & Ex & & & $47 \pm 22$ & 0.6 & $39 \pm 15$ & 0.6 \\
\hline \multirow{2}{*}{$\begin{array}{l}\text { Whole } \\
\text { body }\end{array}$} & Sed & $28,707 \pm 8,043$ & 100 & $7,129 \pm 363$ & 100 & $6,805 \pm 335$ & 100 \\
\hline & Ex & & & $8,043 \pm 655$ & 100 & $7,323 \pm 327$ & 100 \\
\hline
\end{tabular}

${ }^{1}$ Sedentary group. ${ }^{2}$ Exercised group. ${ }^{3}$ Perirenal and inguinal adipose tissues. different $(p<0.05)$ from sedentary group.

exercise period, but there was no significant difference between the two groups.

In heart and adipose tissues, LIPOX contents per rat markedly increased during the first 7 days of the exercise period, and the increases were smaller in exercised rats than in sedentary rats. After 7 days of voluntary running, exercised rats showed significantly lower adipose tissue LIPOX contents per rat $(p<0.05)$ as compared with sedentary rats. In heart and adipose tissues of both groups, LIPOX contents per rat decreased during the last 7 days of the exercise period.

Lung LIPOX contents per rat continuously increased in sedentary rats, while in exercised rats, they increased during the first 7 days and then decreased during the last 7 days of the exercise period.

Brain LIPOX contents per rat progressively elevated throughout the exercise period in both groups of animals, and the increasing rates were considerably larger in exercised rats than in sedentary rats. This resulted in a significantly higher brain LIPOX contents per either $100 \mathrm{~g}$ body weight of rat $(p<0.05)$ in exercised rats at the end of the exercise period as compared with sedentary rats. 
peroxide contents per $100 \mathrm{~g}$ body weight and their percentage distribution in female rats

\begin{tabular}{|c|c|c|c|c|c|c|c|}
\hline \multirow{2}{*}{\multicolumn{2}{|c|}{ Age of rats }} & \multicolumn{6}{|c|}{ Experiment 2} \\
\hline & & \multicolumn{2}{|l|}{31 days } & \multicolumn{2}{|l|}{38 days } & \multicolumn{2}{|c|}{45 days } \\
\hline & & $\begin{array}{l}\text { nmol MDA/ } \\
100 \mathrm{~g} \text { b.w. }\end{array}$ & $\%$ & $\begin{array}{c}\text { nmol MDA/ } \\
100 \mathrm{~g} \text { b.w. }\end{array}$ & $\%$ & $\begin{array}{c}\text { nmol MDA/ } \\
100 \mathrm{~g} \text { b.w. }\end{array}$ & $\%$ \\
\hline \multirow{2}{*}{ Plasma } & $\operatorname{Sed}^{1}$ & $17 \pm 1^{\mathrm{a}}$ & $0.1^{\mathrm{b}}$ & $19 \pm 1^{\mathrm{a}}$ & $0.2^{\mathrm{b}}$ & $16 \pm 1^{\mathrm{a}}$ & $0.2^{\mathrm{b}}$ \\
\hline & $\mathrm{Ex}^{2}$ & & & $17 \pm 1$ & 0.2 & $15 \pm 1$ & 0.2 \\
\hline \multirow{2}{*}{ Carcass } & Sed & $52,392 \pm 9,736$ & 96.6 & $8,672 \pm 467$ & 79.7 & $6,971 \pm 405$ & 81.4 \\
\hline & Ex & & & $8,532 \pm 1,453$ & 81.7 & $5,765 \pm 175^{*}$ & 80.5 \\
\hline \multirow{2}{*}{ Brain } & Sed & $244 \pm 32$ & 0.4 & $302 \pm 22$ & 2.8 & $320 \pm 37$ & 3.9 \\
\hline & Ex & & & $357 \pm 83$ & 3.6 & $451 \pm 73^{*}$ & 6.2 \\
\hline \multirow{2}{*}{ Liver } & Sed & $1,198 \pm 53$ & 2.1 & $747 \pm 46$ & 6.9 & $641 \pm 25$ & 7.8 \\
\hline & Ex & & & $817 \pm 42$ & 8.5 & $637 \pm 37$ & 8.9 \\
\hline \multirow{2}{*}{ Heart } & Sed & $60 \pm 3$ & 0.1 & $85 \pm 7$ & 0.8 & $61 \pm 5$ & 0.7 \\
\hline & Ex & & & $71 \pm 7$ & 0.7 & $52 \pm 4$ & 0.7 \\
\hline \multirow{2}{*}{ Lungs } & Sed & $131 \pm 17$ & 0.2 & $128 \pm 16$ & 1.2 & $152 \pm 22$ & 1.9 \\
\hline & Ex & & & $166 \pm 37$ & 1.9 & $108 \pm 13$ & 1.5 \\
\hline \multirow{2}{*}{ Kidneys } & Sed & $181 \pm 13$ & 0.3 & $163 \pm 3$ & 1.5 & $100 \pm 6$ & 1.2 \\
\hline & Ex & & & $146 \pm 11$ & 1.5 & $118 \pm 9$ & 1.7 \\
\hline \multirow{2}{*}{$\begin{array}{c}\text { Adipose } \\
\text { tissue }^{3}\end{array}$} & Sed & $91 \pm 20$ & 0.2 & $537 \pm 96$ & 6.9 & $14 \pm 2$ & 0.2 \\
\hline & Ex & & & $214 \pm 189^{*}$ & 1.9 & $24 \pm 7$ & 0.3 \\
\hline \multirow{2}{*}{$\begin{array}{l}\text { Whole } \\
\text { body }\end{array}$} & Sed & $61,822 \pm 7,629$ & 100 & $10,854 \pm 423$ & 100 & $8,276 \pm 418$ & 100 \\
\hline & Ex & & & $10,318 \pm 1,473$ & 100 & $7,169 \pm 247^{*}$ & 100 \\
\hline
\end{tabular}

${ }^{a}$ Mean \pm SEM for 6 (31 days) or 5 (38, 45 and 59 days) rats. ${ }^{\mathrm{b}}$ Mean. * Significantly

\section{DISCUSSION}

This study presented interesting findings that the amounts of more than $80 \%$ of the total LIPOX in the rat whole body were distributed in the carcass portions regardless of the amounts of whole body LIPOX stores per rat. Carcass obtained here was mainly composed of subcutaneous adipose tissue, skeletal muscle and skin. As abdominal adipose tissues were found to contain only minor parts of body LIPOX stores in the present experiments, LIPOX stored in carcass might be largely accumulated in muscle and skin portions.

Whole body LIPOX stores of 31 day old rats which were previously fed the low LIPOX diets after weaning were significantly higher than those of 45 and 59 days old (experiment 1). A possible transference of LIPOX from mothers to babies through placenta during pregnancy and/or through milk after delivery may at least in part account for such findings. 
In experiment 2, adipose tissues appeared to actively uptake and accumulate LIPOX while carcass was putting out large amounts of LIPOX, suggesting that adipose tissues may have a role of transient stores for LIPOX. However, the LIPOX accumulation in adipose tissues was lowered by voluntary running exercise. This indicates that either an increased lipolytic activity of adipose tissues by exercise training or a smaller uptake of LIPOX released from carcass portions by adipose tissues than by the other tissues might be partly responsible for the lowered LIPOX accumulation in the adipose tissues of exercised rats.

Another interesting finding observed in the present study (experiment 2) was that the brain also appeared to have an active uptake of LIPOX during the period in which the large amounts of stored LIPOX were removed from the animal body. Furthermore, the LIPOX accumulation into the brain was significantly enhanced by daily voluntary running exercise. In experiment 1 , however, such increases in the brain LIPOX levels were not observed in either sedentary or exercised rats. Therefore, the increased LIPOX levels in the rat brain in experiment 2 may not to be due an increased LIPOX formation in the brain tissue per se by exercise but due to an increased transference of LIPOX from carcass and other tissues into the brain. A transient increase of LIPOX in lungs of exercised rats (experiment 2) may also reflect the exercise-induced increase in LIPOX transference into lungs.

The marked increase of LIPOX observed in the brain of rats with voluntary running exercise seemed to be important with regard to the development and prevalence of cerebrovascular diseases.

There has been reported that bouts of exhaustive exercise increased LIPOX levels in liver and muscle (2) and on the contrary, exercise training decreased LIPOX levels in liver and plasma (5) in rats. Our present study, however, has evaluated all the LIPOX distribution in whole animal body and clearly demonstrated that moderate exercise such as voluntary running enhanced the degradation-excretion of LIPOX in the animal body (experiment 2), but did not increase the formationaccumulation of LIPOX (experiment 1). It was also shown that voluntary running exercise may modulate the LIPOX transference between organs and tissues of rats. These findings, therefore, suggest that the exercise-induced increase or decrease of LIPOX levels in certain organs and tissues may not necessarily indicate the net elevation or reduction of lipid peroxidation in those organs and tissues.

This work was presented in part at the Annual Meeting of the Japanese Conference on the Biochemistry of Lipids, Sendai, July, 1982 and shown in Proc. J. C. B. L., 24, 421-424 (1982). This work was partly supported by a Project Research Grant to M. Suzuki from The University of Tsukuba, 1982.

\section{REFERENCES}

1) Brady, P. S., Ku, P. K., and Ullrey, D. E. (1978): Lack of effect of selenium supplementation on the response of equin erythrocyte glutathione system and plasma enzymes to exercise. J. Anim. Sci., 47, 492-496. 
2) Brady, P. S., Brady, L. J., and Ullrey, D. E. (1979): Selenium, vitamin E and the response to swimming stress in the rat. J. Nutr., 109, 1103-1109.

3) Dillard, C. J., Litov, R. E., Savin, W. M., Dumelin, E. E., and Tappel, Al. L. (1978): Effects of exercise, vitamin $\mathrm{E}$, and ozone on pulmonary function on lipid peroxidation. J. Appl. Physiol.: Respir. Environ. Exercise Physiol., 45, 927-932.

4) Gee, D. L., and Tappel, Al. L. (1981): The effect of exhaustive exercise on expired pentane as a measure of in vivo lipid peroxidation in the rat. Life Sci., 8, 2425-2429.

5) Tani, Y., and Aoki, M. (1981): Effects of dietary protein levels and exercise on liver and serum lipids composition of rats. Eiyo To Shokuryo (J. Jpn. Soc. Food Nutr. Sci.), 34, 59-64.

6) Suzuki, M., Hashiba, N., and Kajuu, T. (1982): Influence of timing of sucrose meal feeding and physical activity on plasma triacylglycerol levels in rat. J. Nutr. Sci. Vitaminol., 28, 295-310.

7) Ohkawa, H., Ohishi, N., and Yagi, K. (1979): Assay for lipid peroxides in animal tissues by thiobarbituric acid reaction. Anal. Biochem., 95, 351-358.

8) Yagi, K. (1975): Micro-determination of lipoperoxide in blood plasma or serum. Vitamins (in Japanese), 49, 403-405.

9) Bagdade, J. D., Yee, E., Albers, J., and Pykalisto, O. J. (1976): Glucocorticoids and triglyceride transport: effects on triglyceride secretion rates, lipoprotein lipase, and plasma lipoproteins in the rat. Metabolism, 25, 533-542.

10) International Chemical Union (1947): The modified Lea's method, in Experiments in Agricultural Chemistry (1967) (revised edition with supplement), Vol. 3, ed. by Department of Agricultural Chemistry of Kyoto Univ., Sangyo Tosho Pub. Co., Ltd., Tokyo, p. 1125.

11) Harper, A. E. (1959): Amino acid balance and imbalance. 1. Dietary protein level of protein and amino acid imbalance. J. Nutr., 68, 405-418. 